\section{(- OPEN ACCESS}

\title{
Coiling of ruptured, wide-necked basilar tip aneurysm using double Comaneci technique
}

\author{
Stanimir S Sirakov, ${ }^{1}$ Alexander Sirakov, ${ }^{1}$ Hristo Hristov, ${ }^{2}$ Radoslav Raychev ${ }^{3}$
}

${ }^{1}$ Radiology department, University Hospital St Ivan Rilski, Sofia, Bulgaria

${ }^{2}$ Neurosurgery Department, University Hospital St Ivan Rilski, Sofia, Bulgaria

${ }^{3}$ Department of Neurological Surgery, UCI Health, Los Angeles, California, USA

\section{Correspondence to} Dr. Stanimir S Sirakov, ssirakov@bsunivers.com

Accepted 13 April 2018

Check for updates

To cite: Sirakov SS, Sirakov A Hristov $\mathrm{H}$, et al. BMJ Case Rep Published Online First: [please include Day Month Year]. doi:10.1136/bcr-2017222703

\section{SUMMARY}

In this report, we present a novel technique of successful coil embolisation using temporary deployment of two Comaneci devices placed in Y configuration across a wide-neck ruptured basilar tip aneurysm. The placement of two devices across the wide aneurysm neck allowed optimal coverage for safe coil delivery, while maintaining parent vessel patency. This case highlights the unique and safe applicability of two crossed Comaneci devices in a ruptured aneurysm with unfavourable anatomy, ultimately resulting in complete aneurysm obliteration. To our knowledge, this is the first reported case of double Comaneci usage in a wide-neck ruptured aneurysm. This technique can be potentially applied in challenging wideneck bifurcation aneurysms, particularly when double antiplatelet therapy is of concern.

\section{BACKGROUND}

Endovascular treatment of ruptured wide-neck basilar tip aneurysms remains a difficult task because of their rare prevalence and specific anatomy. Given the dreadful postrupture clinical outcome and higher rebleeding tendency, the treatment of these lesions requires safe and reliable approach. Various endovascular techniques, such as Y-stenting, balloon-assisted coiling and intrasaccular devices aim at stabilising the coil mass in the target aneurysm. However, some of these techniques have significant limitations in the presence of unfavourable anatomy and subarachnoid haemorrhage due to high risk of thromboembolic complications and the need for double antiplatelet therapy. ${ }^{1-3}$ The new temporary bridging Comaneci is a non-detachable, fully retrievable device designed for bridging aneurysm neck during coil delivery. One of the main advantages of this device is controlled radial expansion to a desired diameter, allowing precise aneurysm neck coverage. Another important advantage of Comaneci is that it does not block the blood flow in the parent vessel during deployment. In addition, no dual antiplatelet therapy is required while it is being used. The fully radiopaque and compliant mesh of the device offers sufficient and stable coverage over the aneurysmal neck. ${ }^{4-6}$

\section{CASE PRESENTATION}

A 40-year-old man with a history of hypertension, smoking and alcohol abuse presented to our hospital with an acute subarachnoid haemorrhage due to a ruptured basilar tip aneurysm. CT angiography confirmed aneurysmal configuration of
$6.8 \mathrm{~mm}$ neck and $8.6 \mathrm{~mm}$ dome. The origins of both posterior cerebral arteries (PCAs) and superior cerebellar artery (SCAs) arose from the very base of the aneurysmal sac. Given the presence of severe subarachnoid hemorrhage (SAH) (Fisher IV), the size and the location of the aneurysm, endovascular approach was considered as the best treatment option after multidisciplinary discussion between interventional neuroradiology and neurosurgery teams.

\section{TREATMENT}

The patient and his relatives were informed about the procedure according to the local institutional policy. Written informed consent was obtained from the patient regarding any possible complications. The aneurysmal embolisation was performed under general anaesthesia and via transfemoral approach. A 6 Fr Chaperon guiding catheter (Microvention) and a $5 \mathrm{Fr}$ guider were navigated in the left and right vertebral arteries over an exchange-length wire. Under roadmap guidance, an Echelon microcatheter was advanced over a microwire inside the aneurysmal sac. Echelon 10 microcatheter was nagivated into both the right and left PCAs and placed distally. The decision of using a COMANECI ' 17 was made on precise measurements of the PCAs and the aneurysmal geometry. The two Comaneci devices were then fully flushed and loaded inside the microcatheters. A few initial loops of the first coil were made to make sure the microcatheter is anchored inside the aneurysmal sac. Each device was then unsheathed by sequential removal of each Echelon microcatheter, while the coil remained undetached within the aneurysm dome. The devices were then carefully expanded across the aneurysm neck by cautious expansion of the bridging mesh via the control handle. Control angiogram was performed to ensure optimal wall apposition and patent flow within the parent and distal vessels (figure 1).

Then, the coil was detached and more coils were delivered within the microcatheter which remained in stable position inside the aneurysm dome. Both devices were manually deflated before detachment of the last coils (figure 2).

Serial control angiograms were performed to confirm successful and safe aneurysmal embolisation. Comaneci device remained deployed for approximately $25 \mathrm{~min}$. No coil protrusion and no complications were observed on the final angiography. Both devices were recaptured into the microcatheter and withdrawn from the parent arteries. 


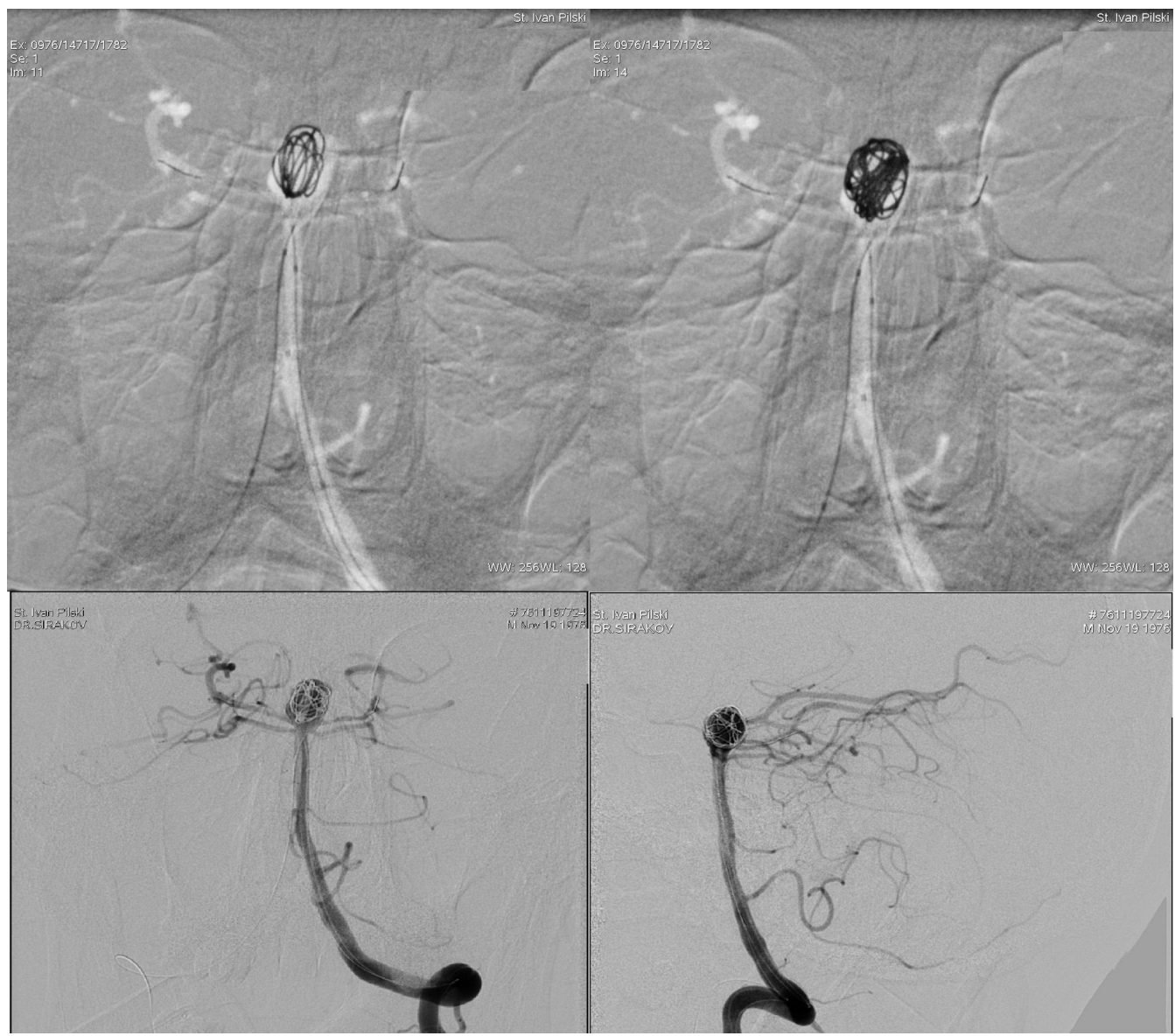

Figure 1 Road map with both expanded devices after placement of the first coil and control angiogram was performed to ensure optimal wall apposition and patent flow within the parent and distal vessels.

Intravenous heparin was administered during the procedure to maintain an activated clotting time between 250 and 300 s. No dual antiplatelet therapy was assigned to the patient before and after the treatment.

\section{OUTCOME AND FOLLOW-UP}

Almost complete aneurysmal occlusion was observed at the conclusion of the treatment with minimal contrast penetration at the base of the coil mass (figure 3 ). The patient recovered fully after the procedure and the subarachnoid haemorrhage. The neurological examination at discharge showed no abnormalities or acquired deficits. On the third-month follow-up angiogram, there was no evidence of aneurysmal recurrence or coil compaction with no visible contrast penetration within the coil mass, compatible with complete obliteration (figure 4).

\section{DISCUSSION}

To our knowledge, this is the first case report describing a temporary neck bridging technique during coil embolisation with double Comaneci device placement, ultimately resulting in successful embolisation of a ruptured wide-neck basilar tip aneurysm, while maintaining parent vessel patency. To date, all published case-series report usage of Comaneci device in unruptured aneurysms in anterior circulation. In addition, some authors have suggested the need of double antiplatelet therapy to prevent any possible device-related complications. In the present case, the patient did not receive any antiplatelet therapy, and no thromboembolic complications were observed.
There are multiple published case-series and papers describing various neck-bridging techniques such as Y-stenting and balloon-assisted coiling in the treatment of ruptured wide-neck basilar tip aneurysms, ${ }^{67}$ however our careful literature observation showed no report of double Comaneci technique in the treatment of such lesions.

The main advantages and technological difficulties in applying the aforementioned techniques are well known and carefully studied. ${ }^{8}$ In a rupture case scenario with presence of subarachnoid

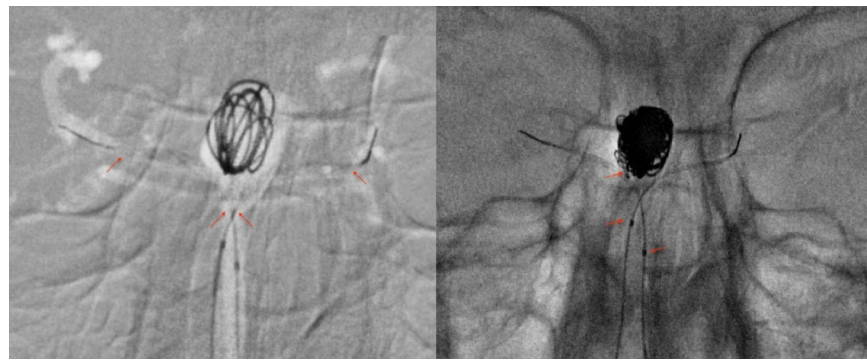

Figure 2 Magnified view demonstrating the deployed Comaneci devices form the distal basilar artery into the bilateral posterior cerebral arteries. Arrows point at the proximal and distal markers of the devices. Magnified unsubtracted images at the completion of the case demonstrating stable and unchanged position of the devices (proximal arrows) and slightly deflected distal marker of the microcatheter within the base of the aneurysm, but outside the parent vessel. 


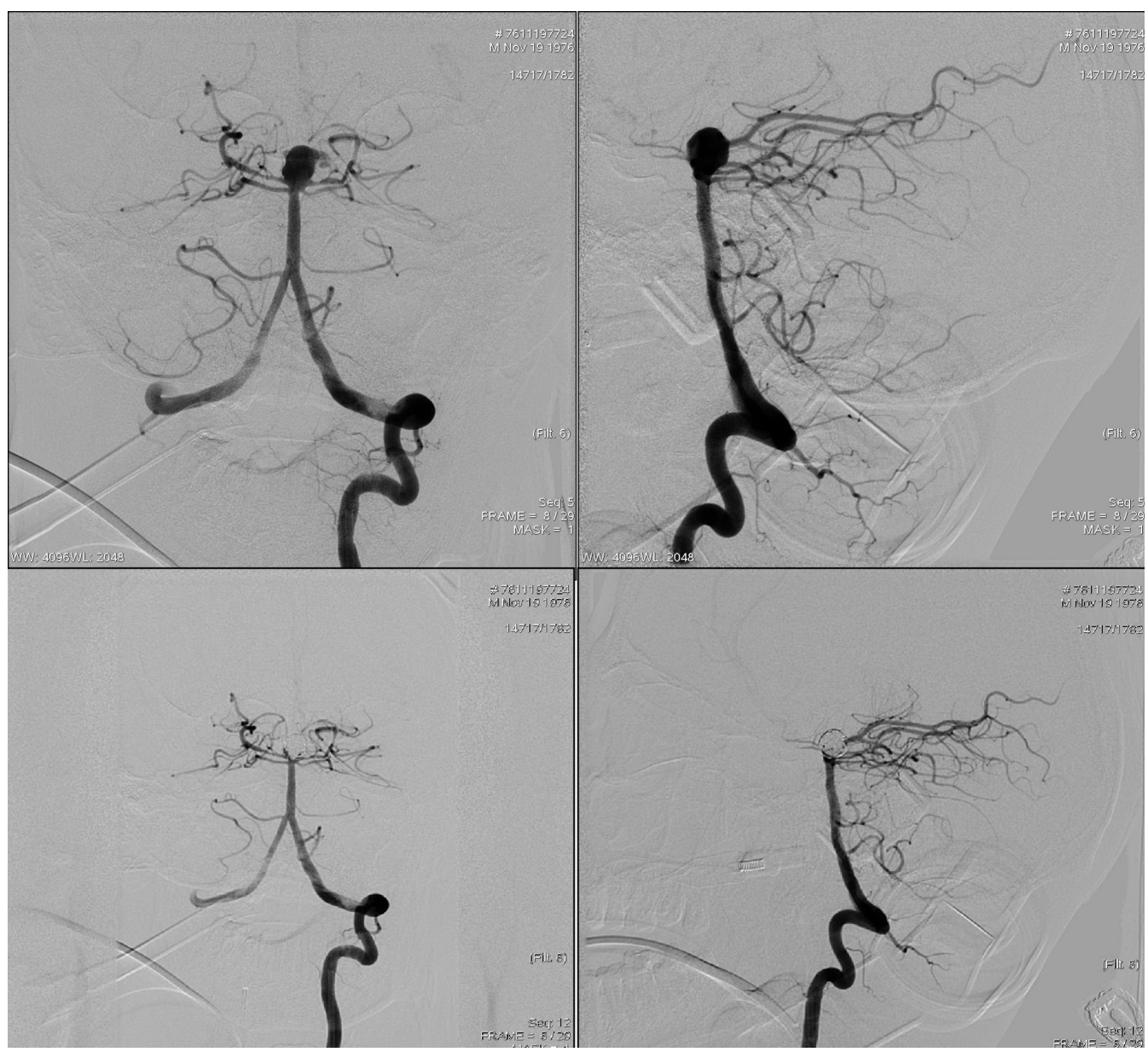

Figure 3 Immediate postprocedure angiogram demonstrating densely packed aneurysm dome with near complete obliteration and widely patent parent posterior cerebral artery and SCAs.

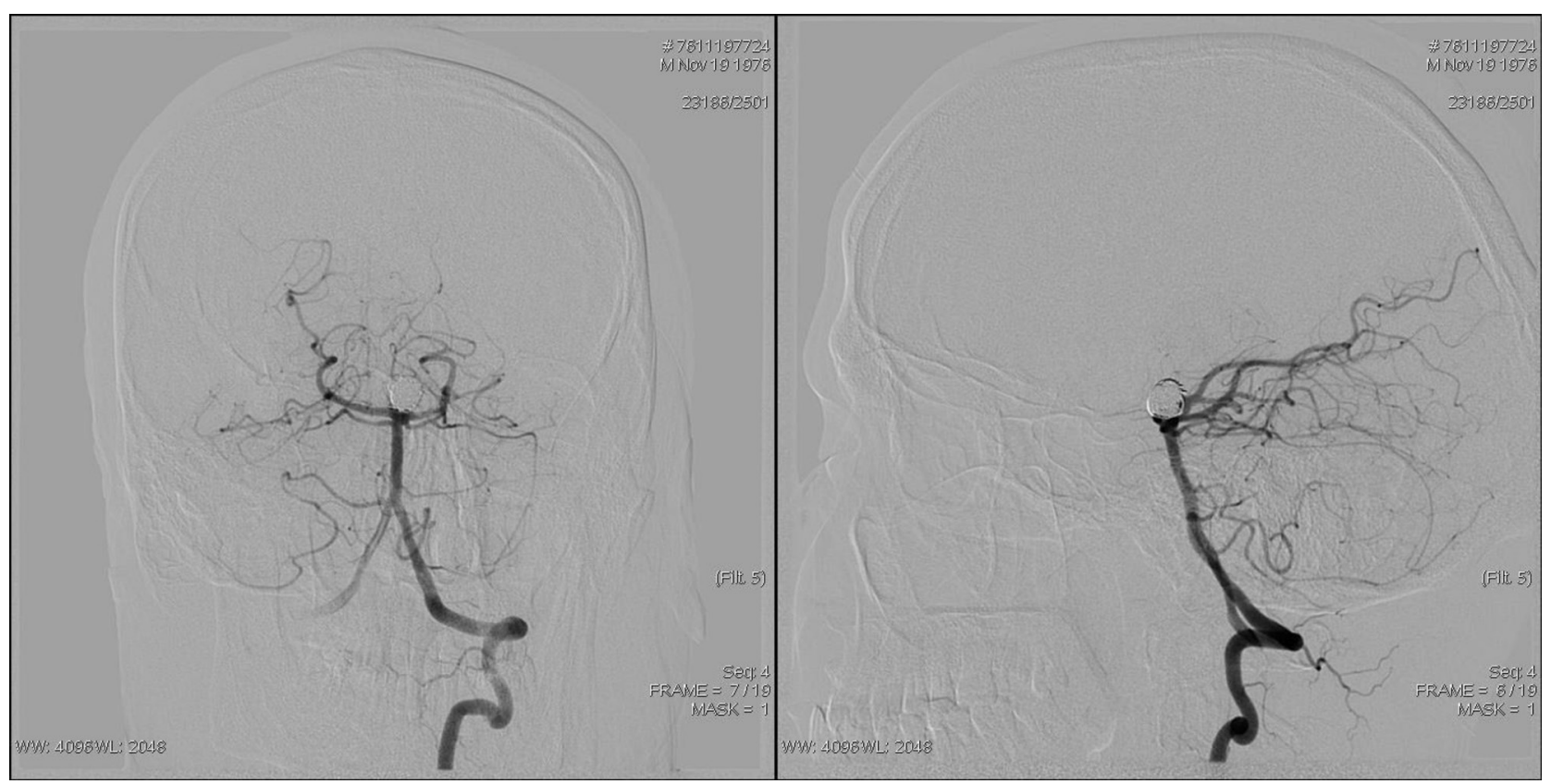

Figure 4 Three-month follow-up angiogram demonstrating completely obliterated aneurysm with no visible contrast penetration within the coil mass and persistently widely patent parent posterior cerebral artery and SCA. 
haemorrhage, thromboembolic complications and parent vessel spasm due to the usage of the device are of theoretical concern. However, no device-related complications were recorded in our initial and early experience with this new temporary bridging device. ${ }^{9}$ This is valid also for this particular case.

We view this technique as a new approach in the endovascular treatment of complex ruptured or unruptured wide-neck aneurysms. The main advantage of using double Comaneci is complete and solid aneurysm neck coverage, allowing intra-aneurysmal coil mass stability and avoidance of parent vessel protrusion. In addition, in our case, the anatomy was particularly challenging as both PCAs were incorporated into the aneurysm base. The radial force of the widely expanded devices in the PCAs allowed persistent parent vessel patency during the coiling and after the completion of the procedure. This technique can be potentially applied in other aneurysms with similar anatomical configuration, particularly in cases when permanent delivery of intravascular devices within the parent vessels and double antiplatelet therapy are contraindicated.

\section{Learning points}

- Comaneci is an effective novel device for the treatment of complex and wide-neck intracranial aneurysms, particularly in the presence of subarachnoid haemorrhage as no double antiplatelet therapy is necessary during device deployment.

- Double Comaneci placement across a wide-neck basilar tip aneurysm allows optimal neck coverage during coil embolisation, while maintaining parent vessel patency.

- Once properly deployed across the aneurysmal neck, no further deflation and inflation of the devices are required.

- This novel technique may be applied for successful coil embolisation of ruptured wide-neck bifurcation aneurysms.

Contributors All authors, SS, AS and RR, certify that they have participated sufficiently in the work to take public responsibility for the content, including participation in the planning, design, conduct and writing. All persons who meet authorship criteria are listed as authors, and all authors certify that they have managed the case and are responsible for the overall content as guarantor.

Funding The authors have not declared a specific grant for this research from any funding agency in the public, commercial or not-for-profit sectors.

Competing interests None declared.

Patient consent Obtained.

Provenance and peer review Not commissioned; externally peer reviewed.

Open Access This is an Open Access article distributed in accordance with the Creative Commons Attribution Non Commercial (CC BY-NC 4.0) license, which permits others to distribute, remix, adapt, build upon this work non-commercially, and license their derivative works on different terms, provided the original work is properly cited and the use is non-commercial. See: http://creativecommons.org/ licenses/by-nc/4.0/

(C) BMJ Publishing Group Ltd (unless otherwise stated in the text of the article) 2018. All rights reserved. No commercial use is permitted unless otherwise expressly granted.

\section{REFERENCES}

1 Maingard J, Kok HK, Phelan E, et al. Endovascular Treatment of Wide-Necked Visceral Artery Aneurysms Using the Neurovascular Comaneci Neck-Bridging Device: A Technical Report. Cardiovasc Intervent Radiol 2017;40:1784-91.

2 Fischer S, Weber A, Carolus A, et al. Coiling of wide-necked carotid artery aneurysms assisted by a temporary bridging device (Comaneci): preliminary experience. J Neurointerv Surg 2017:9:1039-97.

3 Lawson AL, Chandran A, Puthuran M, et al. Initial experience of coiling cerebral aneurysms using the new Comaneci device. J Neurointerv Surg 2016;8:e32.

4 Henkes H, Weber W. The Past, Present and Future of Endovascular Aneurysm Treatment. Clin Neuroradiol 2015:25 Suppl 2(Suppl 2):317-24.

5 Tjahjadi M, Kim T, Ojar D, et al. Long-term review of selected basilar-tip aneurysm endovascular techniques in a single institution. Interdisciplinary Neurosurgery 2017:8:50-6.

6 Sheth SA, Patel NS, Ismail AF, et al. Treatment of wide-necked basilar tip aneurysm not amenable to Y-stenting using the PulseRider device. BMJ Case Rep 2015;2015:bcr2015011836.

7 Miyachi S, Matsubara N, Izumi T, et al. Stent/balloon combination assist technique for wide-necked basilar terminal aneurysms. Interv Neuroradiol 2013;19:299-305.

8 Bang JS, Kim CH, Kwon BJ, et al. The Difficulties and Risks of Y-Stent-Assisted Coiling: A Comparison of First and Second Stenting Procedures. World Neurosurg 2016:88:146-53.

9 Sirakov S, Sirakov A, Hristov H, et al. Early experience with a temporary bridging device (Comaneci) in the endovascular treatment of ruptured wide neck aneurysms. J Neurointerv Surg 2018:neurintsurg-2017-013641. [Epub ahead of print 6 Feb 2018].

Copyright 2018 BMJ Publishing Group. All rights reserved. For permission to reuse any of this content visit

http://group.bmj.com/group/rights-licensing/permissions.

BMJ Case Report Fellows may re-use this article for personal use and teaching without any further permission.

Become a Fellow of BMJ Case Reports today and you can:

- Submit as many cases as you like

- Enjoy fast sympathetic peer review and rapid publication of accepted articles

- Access all the published articles

- Re-use any of the published material for personal use and teaching without further permission

For information on Institutional Fellowships contact consortiasales@bmjgroup.com

Visit casereports.bmj.com for more articles like this and to become a Fellow 